\title{
Estimation of GNSS tropospheric products and their meteorological exploitation in Slovakia
}

\author{
Martin IMRIŠEK ${ }^{1,2, *}$, Mária DERKOVÁ ${ }^{2}$, Juraj JANÁK ${ }^{1}$ \\ ${ }^{1}$ Department of Theoretical Geodesy, Faculty of Civil Engineering, \\ Slovak University of Technology, Bratislava, Slovak Republic; \\ e-mail: martin.imrisek@stuba.sk, juraj.janak@stuba.sk \\ 2 Slovak Hydrometeorological Institute, Bratislava, Slovak Republic; \\ e-mail: maria.derkova@shmu.sk
}

\begin{abstract}
This paper discusses the in near-real time processing of Global Navigation Satellite System observations at the Department of Theoretical Geodesy at the Slovak University of Technology in Bratislava. Hourly observations from Central Europe are processed with 30 minutes delay to provide tropospheric products. The time series and maps of tropospheric products over Slovakia are published online. Zenith total delay is the most important tropospheric parameter. Its comparison with zenith total delays from IGS and E-GVAP solutions and the validation of estimated zenith total delay error over year 2018 have been made. Zenith total delays are used to improve initial conditions of numerical weather prediction model by the means of the three-dimensional variational analysis at Slovak Hydrometeorological Institute. The impact of assimilation of different observation types into numerical weather prediction model is discussed. The case study was performed to illustrate the impact of zenith total delay assimilation on the precipitation forecast.
\end{abstract}

Key words: GNSS processing, zenith total delay, data assimilation, numerical weather prediction model

\section{Introduction}

The processing of Global Navigation Satellite System (GNSS) observations has a long tradition at the Department of Theoretical Geodesy at the Slovak University of Technology in Bratislava. Since 2009, the sub network of EUREF Permanent Network (EPN) and Central European Permanent (CEPER) network were designed to estimate coordinates, tropospheric and

\footnotetext{
${ }^{*}$ corresponding author: e-mail: martin.imrisek@stuba.sk
} 
ionospheric parameters for site velocities estimates and for the determination of Precipitable Water Vapour (PWV) over the observing stations (Hefty et al., 2009).

The tropospheric parameters express the impact of refraction of transmitted signals from GNSS satellites to receivers on Earth. This refraction is denoted as tropospheric delay and it is a consequence of the propagation of GNSS signals through dry gases and water vapour in the atmosphere. The delay caused by dry gases is stable and can be modelled with high precision: Saastamoinen (1972), Niell (1996), Hopfield (1969), Henriksen et al. (1972), Global Mapping Function (Böhm et al., 2006a) combined with Global Model of Pressure and Temperature (Böhm et al., 2007) and with Vienna Mapping Function (Böhm et al., 2006b) combined with ECMWF model. On the other hand, the delay caused by water vapour is not stable and the distribution does not correspond to the dry gases. Nearly half of the total atmospheric water vapour is accumulated between sea level and about $1.5 \mathrm{~km}$ altitude, the other $45 \%$ of the water vapour is distributed up to the altitude of $5 \mathrm{~km}$.

The GNSS observation processing at the Department of Theoretical Geodesy focused mainly on tropospheric parameters was described in Igondová and Cibulka (2010). This network consisted of 58 GNSS permanent stations, it was processed four times per day (at 03, 09, 15, 21 Universal Coordinated Time (UTC)) from four one-hour GNSS data files with a two hours delay. We have developed a new system for estimating the tropospheric parameters ${ }^{1}$ in near real-time and their conversion to various tropospheric products.

Multiple GNSS networks are nowadays processed at the Department of Theoretical Geodesy. In general the networks can be distinguished according to the latency. The final solutions of the sub network of EPN and CEPER network are estimated with two and three weeks latency based on daily observation files with the Precise Network Positioning (PNP) method. On the contrary, the networks processed in near-real time have latency in minutes after the hourly observation files are downloaded.

The requirements for tropospheric parameters estimated in near-real time are following: (i) the tropospheric parameters should representatively describe the state of troposphere, (ii) the latency should be small to satisfy

\footnotetext{
${ }^{1}$ with addition of tropospheric gradients
} 
the needs of numerical weather nowcasting systems. These two requirements are in contradiction. Therefore a balance between these two requirements and optimal processing strategy should be implemented to satisfy these requirements.

The GNSS tropospheric products are becoming an important source of information that is improving the description of the water vapour distribution in the atmosphere. Many meteorological institutes utilize Zenith Total Delay (ZTD) estimates in their global and limited area Numerical Weather Prediction (NWP) models (Guerova et al., 2016). ZTD data enter the data assimilation systems as a valuable complementary observation of humidity with high spatial and temporal resolution. These features are essential to describe the high impact weather phenomena associated with moisture processes. Recently, the benefit of the utilization of the GNSS tropospheric products in numerical weather prediction in Europe has been widely demonstrated. Poli et al. (2007) developed an assimilation methodology of ZTD data in the global model and observed their positive impact over different meteorological regimes. In limited area NWP models various improvements in moisture-related parameters by ZTD data assimilation were shown as well. In Storto and Randriamampianina (2010) improvement in shortrange humidity forecasts in winter period was discussed. The paper Mile et al. (2019) shows the error reduction of NWP derived values of two meter temperature and humidity. Mahfouf et al. (2015) demonstrates better localisation and intensity of forecasted precipitation for Application de la Recherche à l'Opérationnel à Méso-Échelle (AROME)/France NWP model.

At Slovak Hydrometeorological Institute (SHMU) currently only the measurements from the surface weather stations are used operationally for data assimilation purposes (Derková et al., 2017). However, in the preparation of the future setup of the convection resolving numerical weather prediction system there are several activities ongoing to explore the potential of high resolution data assimilation. Among others, in the frame of cooperation between SHMU and the Department of Theoretical Geodesy the ZTD data assimilation procedure is being investigated.

The aim of this paper is to summarize the current state of GNSS processing activities at the Department of Theoretical Geodesy and to demonstrate the potential of application of GNSS products in the numerical weather analysis and prediction system at the SHMU. The influence of the atmo- 
sphere on the propagation of the GNSS signals is described in the Sec. 2 . The Sec. 3 presents the setup of routine processing of GNSS measurements. Validation of estimated ZTD is discussed in the Sec. 4. Various tropospheric products and transformation of ZTD to PWV are described in the Sec. 5 . Exploitations of tropospheric products in meteorology are presented in the Sec. 6 .

\section{GNSS observations and the atmosphere}

The signals from GNSS are bent while propagating through the atmosphere due to ionospheric and tropospheric refraction. This bent causes delay, which affects the measured pseudorange and carrier phase from satellites to receiver on the ground. Ionospheric delay can be effectively removed by processing strategy or with ionospheric correction. The tropospheric delay has to be modelled and estimated together with other parameters e.g. coordinates, clock correction etc.

The pseudorange measurement $P_{k}^{i}$ for satellite $i$ and receiver $k$ may be expressed as:

$P_{k}^{i}=\rho_{k}^{i}+\Delta \rho_{k}^{i}+I_{k}^{i}+T_{k}^{i}+c \delta_{k}-c \delta^{i}$,

where

$\rho_{k}^{i}$ is the geometric range between satellite $i$ and receiver $k$,

$\Delta \rho_{k}^{i}$ is the sum of relativistic effects, instrumental delays, multipath and receiver noise,

$T_{k}^{i}$ is the tropospheric delay for satellite $i$ and receiver $k$,

$I_{k}^{i}$ is the ionospheric delay for satellite $i$ and receiver $k$,

$c$ is the speed of light in vacuum,

$\delta_{k}$ is the receiver clock offset from the GNSS time scale,

$\delta^{i}$ is the satellite clock offset from the GNSS time scale.

Besides the pseudorange, carrier phase $L_{k}^{i}$ is also used to obtain a measure of the apparent distance between the satellite and receiver. These carrier phase measurements are much more precise than the code measurements (typically two orders of magnitude more precise), but they are ambiguous by an unknown integer number of wavelengths $\left(\lambda n_{k}^{i}\right)$. The carrier phase measurement $L_{k}^{i}$ for satellite $i$ and receiver $k$ may be expressed as: 
$L_{k}^{i}=\rho_{k}^{i}+\Delta \rho_{k}^{i}-I_{k}^{i}+T_{k}^{i}+c \delta_{k}-c \delta^{i}+\lambda n_{k}^{i}$,

where

$\lambda$ is the wavelength of transmitted signal,

$n_{k}^{i}$ is the integer ambiguity.

From now on only the tropospheric delay will be discussed in this paper. The ionospheric delay, relativistic effects, instrumental delays, multipath and receiver noise etc. can be eliminated by processing strategy or by precomputed corrections from global analysis center International GNSS Service (IGS). The tropospheric delay, denoted as Slant Total Delay (STD), can be expressed as:

$T_{k}^{i}=m f_{h}(e) Z H D+m f_{w}(e) Z W D+m f_{g}(e)\left[G_{N} \cos (A)+G_{E} \sin (A)\right]$,

where

$e$ is the elevation of measurement,

$A$ is the azimuth of measurement,

$m f_{h}$ is the coefficient of hydrostatic mapping function,

$m f_{w}$ is the coefficient of wet mapping function,

$m f_{g}$ is the coefficient of gradient mapping function estimated as:

$$
m f_{g}(e)=\frac{1}{\sin (e) \tan (e)+0.0032} \text { according to Chen and Herring (1997), }
$$

$Z H D$ is the zenith hydrostatic delay,

$Z W D$ is the zenith wet delay,

$G_{N}$ is the north tropospheric gradient,

$G_{E}$ is the east tropospheric gradient.

The terms of Eq. (3) express slant hydrostatic delay $\left(m f_{h}(e) Z H D\right)$, slant wet delay $\left(m f_{w}(e) Z W D\right)$ and gradient delay $\left(m f_{g}(e)\left[G_{N} \cos (A)+G_{E}\right.\right.$ $\sin (A)])$ from satellite $i$ to receiver $k$ respectively. In the estimation of parameters it is not possible to obtain the tropospheric delay for each measurement (the design matrix would be singular). Hence, the ZTD of receiver is estimated from longer time period. The ZTD can be divided, similarly to tropospheric delay, to hydrostatic Zenith Hydrostatic Delay (ZHD) and wet component Zenith Wet Delay (ZWD) (Davis et al., 1985). The ZHD is 
caused by the dry gases present in the atmosphere. This component is relatively stable and can be sufficiently modelled by climatological or numerical weather prediction model. The hydrostatic delay is about 2.3 meters in zenith and about 10 meters in $10^{\circ}$ elevation. On the other hand, the ZWD varies more with change of local weather conditions. The delay caused by water vapour and condensed water in form of clouds is ranging from 0.1 meters in winter to 0.3 meters in summer.

Tropospheric products are widely exploited in the NWP modelling. These data can be used to improve initial conditions of NWP model.

\section{Estimation of zenith total delay}

The processing of the hourly GNSS measurements is carried out in near real-time each hour with PNP method at the Department of Theoretical Geodesy at the Slovak University of Technology (SUT) in Bratislava ${ }^{2}$ from 2016. The network consists of 59 permanent GNSS stations (Fig. 1). Hourly data are downloaded from regional data centre Federal Office of Metrology and Surveying Austria (Sehnal et al., 2019), Bundesamt für Kartographie und Geodäsie (Bruyninx et al., 2012) and local data centre at the Department of Theoretical Geodesy. The data files are stored in Receiver INdependent EXchange format (RINEX) version 2.11 (IGS, 2019) which includes Global Positioning System (GPS) and Globalnaya Navigatsionnaya Sputnikovaya Sistema (GLONASS) measurements only. The coordinates and tropospheric parameters are estimated by multi-GNSS data processing software developed at the Astronomical Institute of the University of Bern version 5.2 (Dach et al., 2015). All mandatory files required for processing are downloaded from Center for Orbit Determination in Europe (CODE) data centre. The rapid Earth orientation parameters, ionospheric corrections and satellite clock corrections (Dach et al., 2018) are downloaded from the CODE data centre as well. The rapid satellite positions are primarily downloaded from IGS. In case the combined solution is not available the CODE solution is downloaded.

The a priori coordinates of permanent GNSS stations are interpolated to processing epoch from EPN multi-year position and velocity solution

\footnotetext{
${ }^{2}$ described as SUT solution
} 


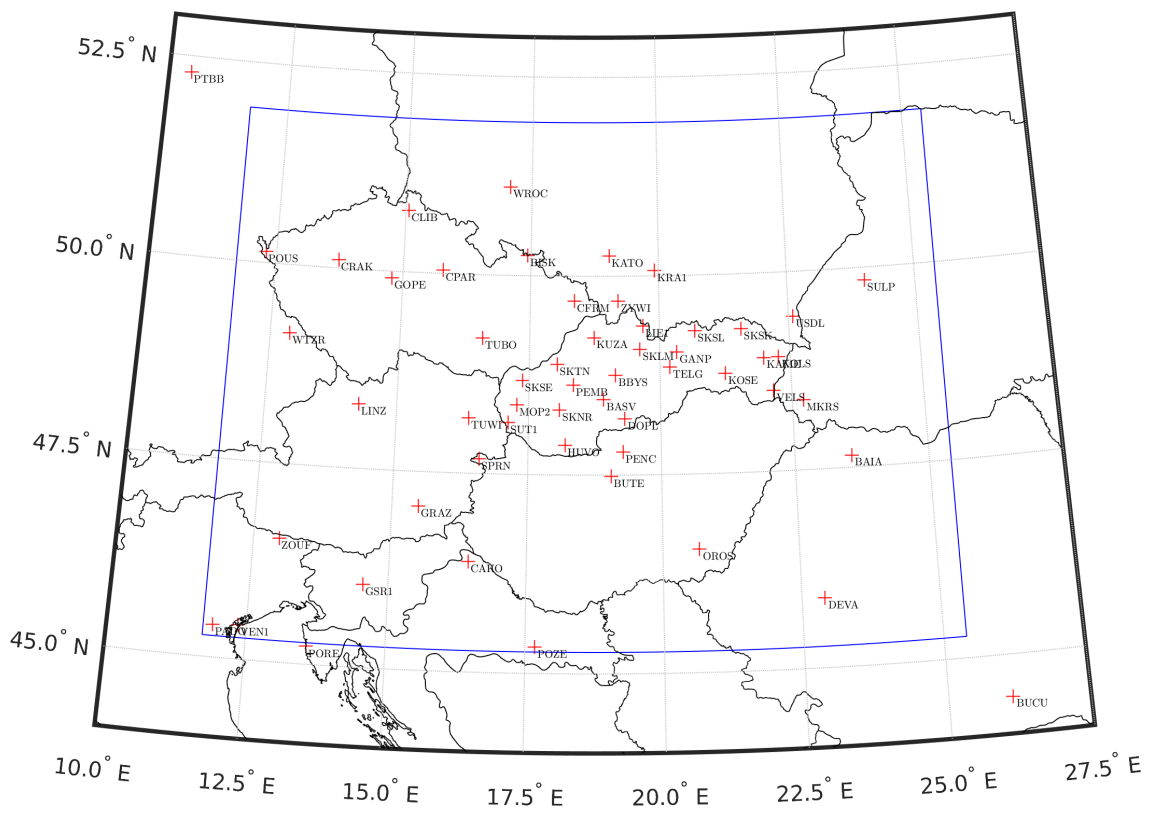

Fig. 1. Map of GNSS permanent stations and NWP domain of AROME/SHMU (blue polygon).

in reference frame IGS14. A priori coordinates for stations not included in EPN are computed from stable ten days long time series. The position from site $\log$ file is used as a priori coordinates if the station has not long enough time series of coordinates, or the time series have standard deviation more than $10 \mathrm{~mm}$. The station is excluded from processing if there are any data gaps in last eight hours. This restrictions should provide only estimation of reliable ZTD from the stations without data issues. The PNP method is using baselines to differ observations between permanent GNSS stations. The baselines are created with the OBS-MAX optimization criterion. This method creates baselines upon amount of common time epochs of the same satellite measurements between two stations. The outputs from the Global Model of Pressure and Temperature (Böhm et al., 2007) and Global Mapping Function (Böhm et al., 2006a) are used as a priori ZHD and coefficients of mapping functions in parameter estimation. The model Chen and Herring (1997) is chosen for estimation of tropospheric gradients $G_{N}$ and $G_{E}$. 


\section{Validation of estimated zenith total delay}

Multiple validations of zenith total delays estimated in near real-time were done. First one year long error analysis of ZTD was performed. The second comparison was done between ZTD of SUT and The EUMETNET EIG GNSS water vapour programme (E-GVAP) solutions. The last comparison of ZTD was carried out between SUT and IGS solutions. The choice of permanent stations for validations depended on the status of GNSS network at the time of comparison and on the availability of the tropospheric products from other sources.

\subsection{Zenith total delay error analysis}

The analysis of ZTD was carried out for the year 2018. This analysis was performed over several GNSS permanent stations chosen to represent various regions and to cover the whole network (Fig. 1). The mean error of ZTD at GNSS permanent stations varies from the $0.80 \mathrm{~mm}$ in the winter to $1.56 \mathrm{~mm}$ in the summer. Mean time series of ZTD error are displayed in Table 1 of individual permanent stations in the winter and in the summer 2018.

Table 1. Statistics of ZTD errors in summer and winter period of the year 2018 [mm].

\begin{tabular}{lcccc}
\hline Station & \multicolumn{2}{c}{ Winter } & \multicolumn{2}{c}{ Summer } \\
& & $\begin{array}{c}\text { Standard } \\
\text { deviation }\end{array}$ & Mean & $\begin{array}{c}\text { Standard } \\
\text { deviation }\end{array}$ \\
\hline BASV & 0.91 & 0.094 & 1.14 & 0.158 \\
BBYS & 0.87 & 0.102 & 1.06 & 0.154 \\
BUCU & 1.03 & 0.102 & 1.31 & 0.197 \\
DEVA & 1.22 & 0.121 & 1.51 & 0.235 \\
GANP & 0.85 & 0.090 & 1.06 & 0.153 \\
GRAZ & 0.83 & 0.082 & 1.04 & 0.155 \\
TUBO & 0.80 & 0.086 & 1.01 & 0.150 \\
WTZR & 0.84 & 0.090 & 1.08 & 0.312 \\
ZIMM & 1.23 & 0.140 & 1.56 & 0.245 \\
\hline
\end{tabular}

The mean ZTD errors are $25 \%$ higher in the summer than in the winter. This difference is caused by increased content of water vapour in the atmosphere in the summer period. The hot air has bigger water vapour capacity 
than the cold air and contains more water vapour. The ZTD errors at 00 and 12 UTC were compared for the whole year. No significant increase due to diurnal cycle was detected. Fig. 2 displays the ZTD error time series of the station TUBO (Vysoké učení technické v Brně, Czech Republic). This station has the lowest mean error in the winter and in the summer.

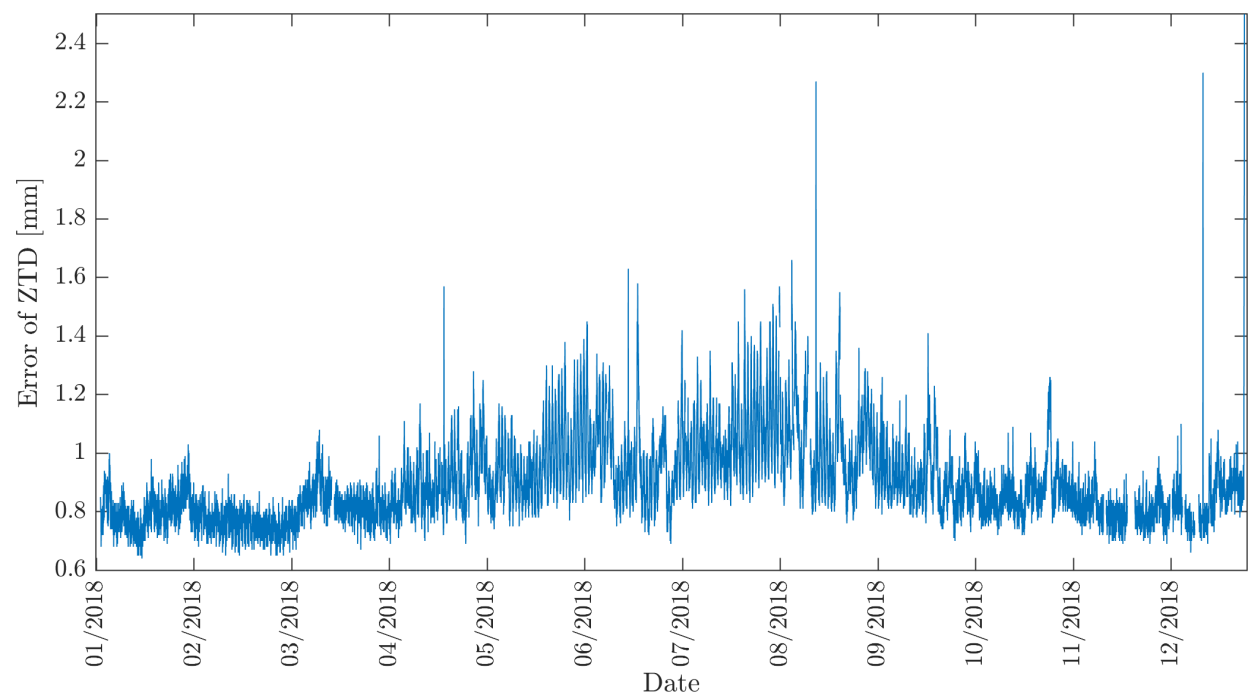

Fig. 2. Zenith total delay error time series $[\mathrm{mm}]$ of the year 2018 for the permanent station TUBO.

On the other hand, the permanent station ZIMM (Zimmerwald, Switzerland) has the highest mean winter and summer error of estimated ZTD. Fig. 3 displays the ZTD error time series of the station ZIMM.

The mean winter and summer ZTD error is about $53 \%$ and $54 \%$ higher at the permanent GNSS station ZIMM than at the station TUBO respectively. This increase might be caused by two reasons. The minor reason might be the different orographic obstacles in horizon and the environment in which the stations are located. While station TUBO is located on flatland in city, permanent station ZIMM is in agricultural environment in Alps. The main reason may be related to the received measurements from satellite systems. While the station ZIMM receives only signals from navigational system GPS, the other stations receive signals also from satellite system GLONASS. The lack of GLONASS observations has impact on the estima- 


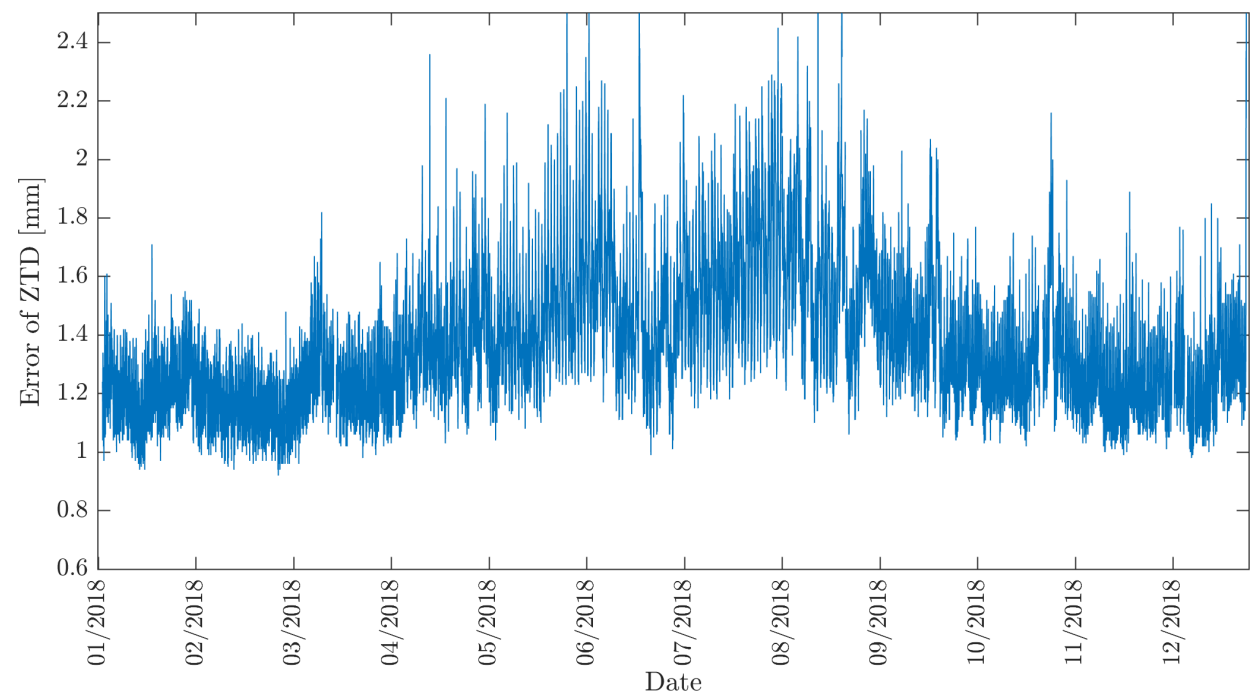

Fig. 3. Zenith total delay error time series [mm] of the year 2018 for the permanent station ZIMM.

tion of ZTD. Stations receiving multiple GNSS have better space coverage of the atmosphere from different directions. This assumption was affirmed by error of station DEVA (Deva, Romania), which has also about $50 \%$ higher error of estimated ZTD compared to stations receiving signals from multiple GNSS (Table 1). This stations is also not receiving signals from GLONASS. Overall, the error of estimated zenith total delay is only $0.05 \%$ of its absolute value. Therefore we can consider estimated ZTD suitable for further comparison with ZTD from other sources.

\subsection{Comparison of SUT and E-GVAP solutions}

The comparison with ZTD obtained from independent E-GVAP project (Guerova et al., 2016) was done. This programme collects and processes GNSS data from over 1800 European permanent stations in near real-time with PNP method. The comparison was done between 1 and 26 October 2016 on three permanent stations BBYS (Banská Bystrica, Slovakia), CFRM (Frýdek Místek, Czech Republic) and TUBO. Time series of SUT and E-GVAP ZTD for station TUBO is plotted in Fig. 4. The differences are computed as E-GVAP solution minus SUT solution. 


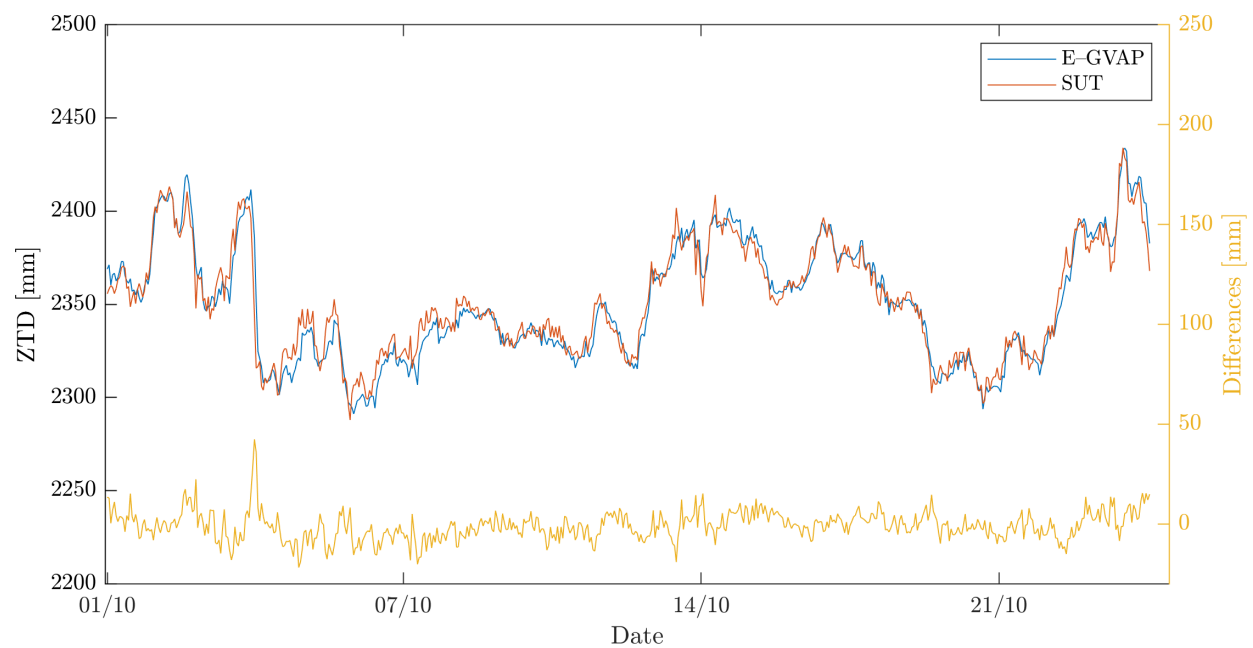

Fig. 4. Comparison of ZTD [mm] between SUT and E-GVAP solutions from 1 to 26 October 2016 at station TUBO.

These differences are shown in Table 2. Mean values of differences are relatively small (only $0.05 \%$ of absolute value) and they are comparable to the estimated ZTD error (Table 1). The positive correlations were found for all stations. Small mean differences and positive correlation coefficients declares high fit between SUT and E-GVAP solution. The highest peaks in differences are caused by different time of detection of the ZTD change. The absolute values of ZTD are approximately the same. When a sudden change of weather occurs the SUT and E-GVAP solutions are slightly shifted.

Table 2. Statistics of ZTD differences between SUT and E-GVAP solutions [mm].

\begin{tabular}{lccc}
\hline & BBYS & CFRM & TUBO \\
\hline Mean value & -1.8 & -1.6 & -1.0 \\
Standard deviation & 8.17 & 7.30 & 7.18 \\
Correlation coefficient & +0.980 & +0.978 & +0.975 \\
\hline
\end{tabular}

\subsection{Comparison of SUT and E-GVAP solutions}

The comparison was made between SUT and IGS solutions. The IGS service provides final solution with 21 days delay estimated with Precise Point Positioning (PPP) method for permanent GNSS stations included in IGS 
network. The following GNSS permanent stations from IGS network are processed in the SUT solution: BUCU (Bucuresti, Romania), GANP (Gánovce, Slovakia), GRAZ (Graz, Austria), GOPE (Ondřejov, Czech Republic), PENC (Penc, Hungary), WROC (Wroclaw, Poland), WTZR (Bad Koetzting, Germany) and ZIMM (Zimmerwald, Switzerland). The IGS solution is estimated with different approach and the most precise corrections. This makes IGS solution suitable for comparison. Comparison was done on one month period of February 2019. The time series of ZTD and differences for GANP station are displayed in Fig. 5. The differences are computed as IGS solution minus SUT solution.

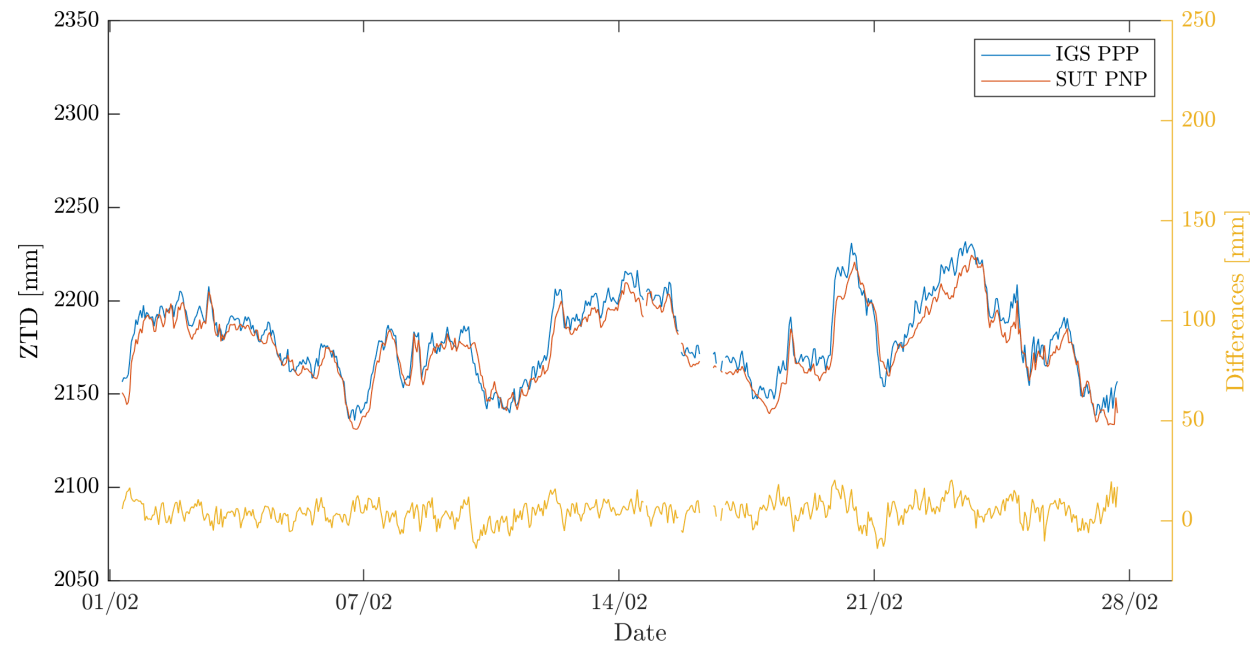

Fig. 5. Comparison of ZTD [mm] at station GANP between SUT and IGS solutions from 1 to 28 February 2019.

The gaps in time series are the consequence of the temporal data unavailability at the station. The mean absolute values of differences for stations are approximately twice bigger than in E-GVAP comparison, but it is only $0.2 \%$ of the ZTD. The differences are mainly caused by different processing approach. In PPP method there are no baselines created, so the estimated parameters are independent from measurements of another station. Mean differences, standard deviations and correlation coefficients are shown in Table 3. 
Table 3. Statistics of ZTD [mm] differences between SUT and IGS solutions [mm].

\begin{tabular}{lccc}
\hline & GANP & GRAZ & WTZR \\
\hline Mean value & 4.5 & 4.2 & 4.4 \\
Standard deviation & 5.60 & 5.50 & 5.15 \\
Correlation coefficient & +0.965 & +0.971 & +0.978 \\
\hline
\end{tabular}

The decrease of standard deviation of differences is about $30 \%$ in respect to E-GVAP. Positive and high correlation coefficients declare very good agreement of ZTD between SUT and IGS solution. Nowadays, the comparison is available after each processing for all IGS stations processed in SUT solution. This comparison is available on public web page together with other tropospheric products, more in section 5 .

\section{Tropospheric products}

As demonstrated in the previous sections, the SUT solution provides reliable ZTD comparable quality to the products from E-GVAP and IGS. Therefore, based on this conclusion, the SUT data are further processed, visualised and made available via public web page http://space.vm.stuba.sk/pwv graph/space.vm.stuba.sk/pwvgraph/ hosted on local server at the Department of Theoretical Geodesy. Multiple products and additional information about the processing for chosen stations are online:

- 31 day long time series of ZTD,

- 31 day long time series of PWV,

- 31 day long time series of $G_{N}$ and $G_{E}$,

- last 5 hours of ZTD maps (see Fig. 6),

- last 5 hours of PWV maps (see Fig. 7),

- vertical and horizontal cross sections of GNSS tomography valid for last processing,

- time series of position differences between SUT and EPN solutions,

- station data availability statistic for last day, last 7 and 31 days,

- complete processing summary from Bern GNSS software valid for last processing.

The GNSS tomography is a technique to estimate three-dimensional information about a humidity distribution in the troposphere. This estimation 
is based on intersection of GNSS signals from different satellites and permanent stations. The tomographic reconstruction is carried out every hour and it is based on Bender et al. (2011). The STD (Eq. 3) is computed from azimuth and elevation to satellites and Global Mapping Function with atmospheric parameters. Azimuth and elevation to satellite is derived from satellite position and station coordinates. The atmospheric parameters are derived from operational Aire Limitée Adaptation dynamique Développement InterNational (ALADIN)/SHMU NWP model (Derková et al., 2017).

The ZTD values in maps over Slovakia are transformed to mean sea level pressure for better visualization. The dependency of ZTD on station altitude is reduced to minimum by adding model zenith total delay corresponding to its altitude. After this transformation the isolines are smooth and the values are more consistent ${ }^{3}$ as it is displayed in Figs. 6 and 7.

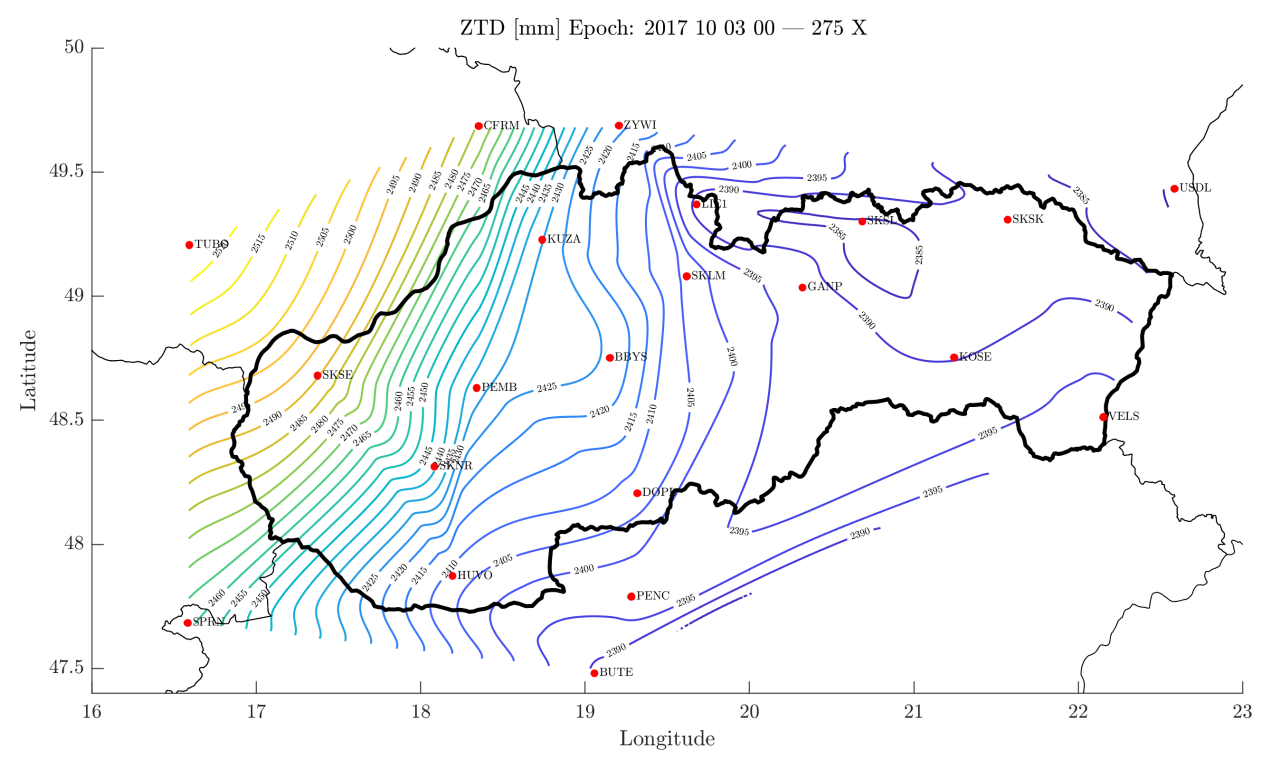

Fig. 6. Map of zenith total delay [mm] over Slovakia on 3 October 2017.

The transformation of ZTD to PWV is proposed in Bevis et al. (1994). Meteorological data are required for this transformation. The SHMU is providing temperature, pressure, relative humidity and other atmospheric

\footnotetext{
${ }^{3}$ maps are without big gradients
} 
parameters from operational NWP products for permanent GNSS stations in Slovakia and its vicinity. For this transformation the ZHD is [m] required (Henriksen et al., 1972):

$$
Z H D=10^{-7} k_{1} \frac{R_{d}}{g_{\varphi, H}} p,
$$

where

$k_{1}$ is the physical constant of refraction $\left[77.604 \mathrm{~K} \mathrm{hPa}^{-1}\right]$,

$R_{d}$ is the specific gas constant of dry air $R_{d}=\frac{R}{M_{h}}\left[287.058 \mathrm{~kg}^{-1} \mathrm{~K}^{-1}\right]$,

$R$ is the gas constant $\left[8.3144621 \mathrm{~J} \mathrm{~mol}^{-1} \mathrm{~K}^{-1}\right]$,

$M_{h}$ is the molar mass of the hydrostatic air $\left[0.0289645 \mathrm{~kg} \mathrm{~mol}^{-1}\right]$, $p$ is the atmospheric pressure $[\mathrm{hPa}]$ at station, $g_{\varphi, H}$ is the gravity acceleration $\left[\mathrm{m} \mathrm{s}^{-2}\right]$,

$g_{\varphi, H}=9.784(1-0.00266 \cos (2 \varphi)-0.00000028 H)$,

$H$ is the orthometric height $[\mathrm{m}]$,

$\varphi$ is the ellipsoidal laitude of station.

The ZWD is defined as:

$Z W D=Z T D-Z H D$.

Bevis et al. (1994) proposed the transformation of ZWD to PWV [m]:

$P W V=\frac{\kappa Z W D}{\rho_{w}}$,

where

$\kappa$ is the transformation coefficient $\kappa=\frac{10^{8}}{R_{w}\left(\frac{k_{3}}{T_{m}}+k_{2}-m k_{1}\right)}$,

$k_{2}$ is the physical constant of refraction $22.1 \mathrm{~K} \mathrm{hPa}^{-1}$,

$k_{3}$ is the physical constant of refraction $3.766 \times 10^{5} \mathrm{~K}^{2} \mathrm{hPa}^{-1}$,

$T_{m}$ is the mean temperature of atmosphere $[\mathrm{K}]$ estimated as:

$T_{m}=70.2+0.72 T$,

$T$ is the temperature $[\mathrm{K}]$ at station,

$m$ is the molar mass ratio of the water vapour and hydrostatic air:

$m=\frac{M_{w}}{M_{h}}$, 
$M_{w}$ is the molar mass of the water vapour $\left[0.0180152 \mathrm{~kg} \mathrm{~mol}^{-1}\right]$,

$R_{w}$ is the specific gas constant of the water vapour, estimated as:

$R_{w}=\frac{R}{M_{w}}\left[\mathrm{~kg}^{-1} \mathrm{~K}^{-1}\right]$

$\rho$ is the density of water $\left[998 \mathrm{~kg} \mathrm{~m}^{-1}\right]$.

The PWV represents the amount of water contained in a column of atmosphere above permanent station. Fig. 7 displays the PWV distribution over Slovakia in $[\mathrm{mm}]$. One millimetre of PWV is equal to one litre of water per square meter.

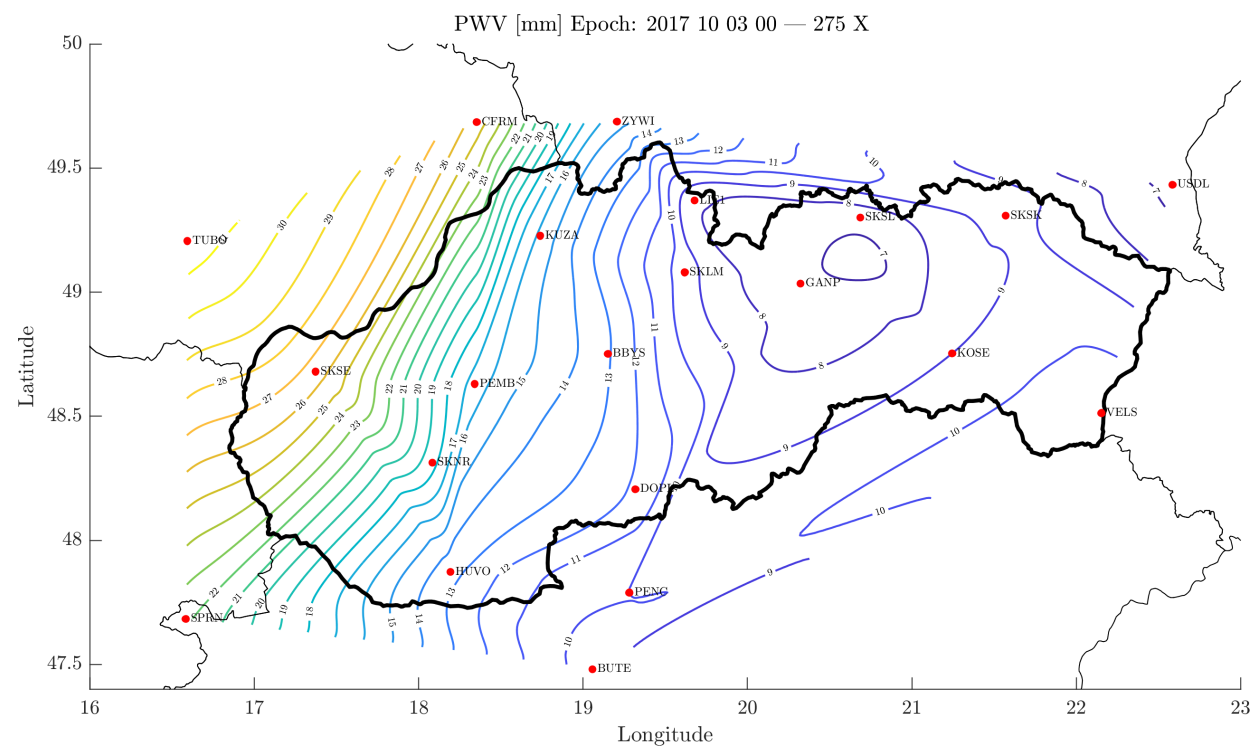

Fig. 7. Map of precipitable water vapour [mm] over Slovakia on 3 October 2017.

\section{Usage of tropospheric products}

The ZTD or derived products can be exploited in detection of large scale atmospheric systems in form of time series, maps and tomographic reconstruction of troposphere (Sec. 6.1). The tomographic reconstruction of fields of wet refractive indexes of the troposphere, which can be transformed to the water vapour content, is not discussed in this paper. The exploitation of ZTD in NWP models is described from Sec. 6.2.3 to 6.2.5. 


\subsection{Detection of large scale atmospheric systems}

Zenith total delays can be used for detection of movement of large scale atmospheric systems. Change of zenith total delay occurs when a large scale atmospheric system is passing above permanent stations. This case study of passing atmospheric system was carried out for a time window from the 27 September to the 3 October 2017. The wet air was pushing dry air containing small amount of water vapour toward south east direction. The amount of water vapour is included in ZTD as ZWD (Eq. 6). This phenomenon is illustrated in map of ZTD over Slovakia (Fig. 6) and derived map of PWV over Slovakia (Fig. 7). The time series of ZTD at selected stations located along the atmospheric system trajectory are plotted in Fig. 8. The individual time series are reduced by their minimum values for better comparison. The approaching atmospheric system is detected by rapid increase of zenith total delay on permanent stations. At first, the atmospheric system moved over station TUBO (Vysoké učení technické v Brně, Czech Republic), then over SKTN (Trenčín, Slovakia), then over GANP (Gánovce, Slovakia) and at last over the station KOSE (Košice, Slovakia).

The station SKTN is not present in Figs. 6 and 7 because the atmospheric data were not available at the moment of case study.

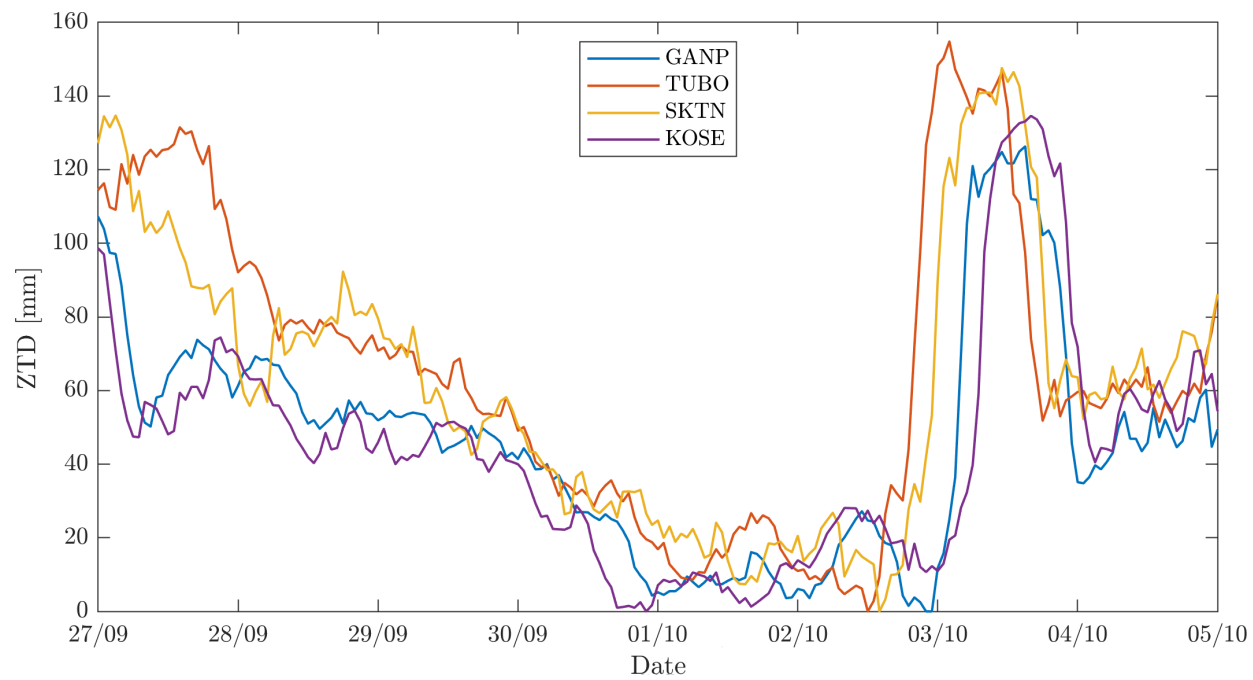

Fig. 8. Time series of differenced ZTD for the selected permanent stations from 27 September to 5 October 2017. 


\subsection{ZTD assimilation into NWP model}

In order to illustrate the potential of exploitation of the ZTD in the high resolution numerical weather forecasting the multiple experiments were conducted at SHMU. The first experiment was a single observation experiment, where we demonstrated impact of one assimilated zenith total delay on numerical weather prediction model. The second experiment compares the impact of assimilation of ZTD with respect to other types of observations. The last experiment demonstrates the impact of ZTD assimilation on precipitation forecast.

\subsubsection{Numerical weather prediction model}

At SHMU the ALADIN NWP model (Termonia et al., 2018) - configuration AROME (Seity et al., 2011) is used for data assimilation. The AROME NWP model is adapted to the limited area geometry and the physical parameterization schemes are derived from Meso-NonHydrostatic research model (Lafore et al., 1998). AROME NWP model is experimentally exploited at the SHMU (Derková et al., 2017). The AROME domain covers Slovakia and vicinity. The size and position of AROME domain is displayed in Fig. 1. The horizontal resolution is $2.0 \mathrm{~km}$ on a Lambert projection with $\lambda=\left(11.73^{\circ}, 25.40^{\circ}\right), \phi=\left(45.27^{\circ}, 51.93^{\circ}\right)$ which results to 501 and 373 physical $^{4}$ grid points in the east-west and north-south directions respectively. The domain is vertically divided into 73 levels using a hybrid pressure terrain-following coordinate system. The height of the lowest level ${ }^{5}$ is about $11 \mathrm{~m}$ above the ground. The size and resolution of the domain depends on computing capacities of supercomputer at SHMU. This setup of NWP model is referred to as AROME/SHMU. For NWP forecasting ${ }^{6}$ the boundary conditions are mandatory. The AROME/SHMU model is nested in ALADIN/SHMU (Derková et al., 2017) with hourly coupling frequency.

\subsubsection{Assimilation method}

The initial conditions ${ }^{7}$ for numerical weather forecast can be improved using

\footnotetext{
${ }^{4}$ the most model computation are in spectral space

${ }^{5}$ model level number 73

${ }^{6}$ denoted as integration

${ }^{7}$ the initial state for the integration of the atmospheric model
} 
data assimilation methods. These provide the best possible estimation of the current state of the atmosphere based on the various types of observations and measurements of the atmospheric parameters. Data assimilation is an analysis method in which the observed information is accumulated into the model state by taking advantage of consistency constraints with laws of time evolution and physical properties (Courtier et al., 1991). In the experimental setup of AROME/SHMU the Three-Dimensional Variational analysis (3D-Var) method is used to obtain NWP analysis $\mathbf{x}_{a}$ (Fischer et al., 2005). The principle of 3D-Var method is to estimate an approximate solution to the equivalent minimization problem defined by the cost function (Eq. 8). The solution is sought iteratively by performing several evaluations of the cost function:

$$
\begin{aligned}
& J(\mathbf{x})=\left(\mathbf{x}-\mathbf{x}_{b}\right)^{T} \mathbf{B}^{-1}\left(\mathbf{x}-\mathbf{x}_{b}\right)+(\mathbf{y}-H(\mathbf{x}))^{T} \mathbf{R}^{-1}(\mathbf{y}-H(\mathbf{x})), \\
& J(\mathbf{x})=J_{b}+J_{o},
\end{aligned}
$$

where

$\mathbf{x}$ is the model state,

$\mathbf{x}_{b}$ is the background model state ${ }^{8}$,

$\mathbf{y}$ is the vector of observations,

$H$ is the observation operator,

$\mathbf{B}$ is the covariance matrix of background model state,

$\mathbf{R}$ is the covariance matrix of observations,

$J_{o}$ is the observation cost function,

$J_{b}$ is the background cost function.

An analysis is the production of an accurate image of the true state of the atmosphere at a given time, represented in a model as a collection of numbers. An analysis can be useful in itself as a comprehensive and selfconsistent diagnostic of the atmosphere. It can also be used as input data for a numerical weather forecast, or as a data retrieval to be used as a pseudo-observation. It can provide a reference against which to check the quality of observations (Bouttier and Courtier, 2002).

Zenith total delays can be used stand alone or together with other observations as $\mathbf{y}$ in the $3 \mathrm{D}-$ Var method.

\footnotetext{
${ }^{8}$ denoted as guess
} 


\subsubsection{Single ZTD assimilation experiment}

The first experiment was an assimilation of a single observation into AROME /SHMU NWP model to demonstrate the impact of ZTD observations on the NWP analysis. The ZTD was from station GANP (Gánovce, Slovakia) estimated in near-real time on 15 August 2018 at 12 UTC. This station was chosen due to the stable time series of estimated tropospheric products, due to successful validation with ZTD from other sources and due to approximate position in the middle of NWP domain. The NWP analysis was created by assimilation of the ZTD with 3D-Var method to the background model state of NWP model. The impact of single observation assimilation is computed as difference of analysis and background model state ${ }^{9}$ to show how the information from the assimilated observation propagates horizontally and vertically in space. The impact of single ZTD assimilation on specific humidity is displayed in Fig. 9. As it is shown, the increments at the 65th model level are concentric isolines around the position of assimilated ZTD. Height of the 65 th model level is about $209 \mathrm{~m}$ above terrain.

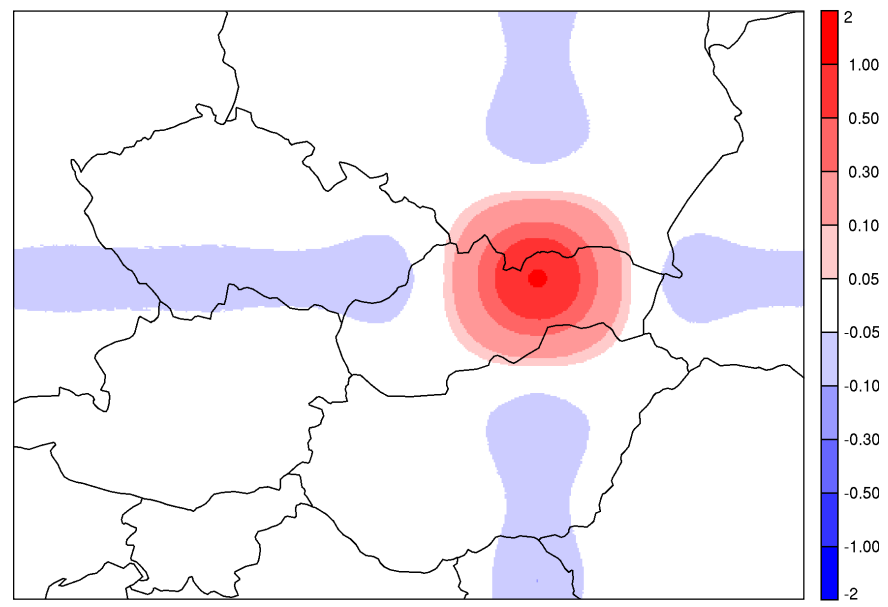

Fig. 9. Increments of specific humidity $\left[1 \times 10^{-4} \mathrm{~kg} \mathrm{~kg}^{-1}\right]$ on 15 August 201812 UTC at model level 65.

The maximum increments of specific humidity reached $1.18 \times 10^{-4} \mathrm{~kg} \mathrm{~kg}^{-1}$ at the 65 th model level in the position of permanent station GANP. Whereby

\footnotetext{
${ }^{9}$ the differences are denoted as increments
} 
the increments are close to zero about $100 \mathrm{~km}$ away from permanent station. The Fig. 10 displays $155 \mathrm{~km}$ east-west direction vertical cross section of increments of specific humidity.

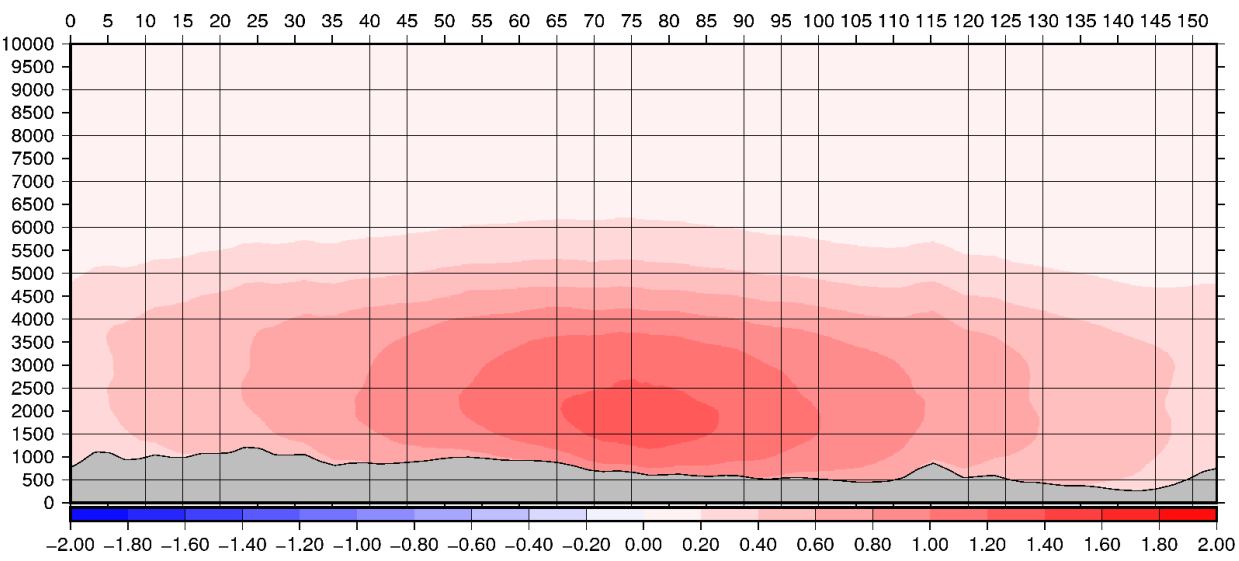

Fig. 10. Specific humidity $\left[1 \times 10^{-4} \mathrm{~kg} \mathrm{~kg}^{-1}\right]$.

The impact of single ZTD assimilation is located in the bottom layers of the troposphere - below the first $5 \mathrm{~km}$ of atmosphere. This result of 3D-Var assimilation method is in agreement with Mockler (1995), who declared that $90 \%$ of water vapour is accumulated in the first $5 \mathrm{~km}$ of troposphere. The difference between estimated ZTD from SUT solution and from the model state estimated by observation operator $H$ decreased after assimilation from $3.79 \mathrm{~mm}$ to $0.35 \mathrm{~mm}$. This decrease illustrates, that the analysis of NWP model has been adapted to assimilated ZTD.

\subsubsection{Impact of ZTD assimilation}

The impact analysis of ZTD assimilation on AROME/SHMU NWP model with respect to other different observation types was carried out. The experiment was performed for two days. First selected day (19 July 2018) represents rainy weather with locally measured precipitation of $110 \mathrm{~mm}$ in $24 \mathrm{~h}$. On the contrary no precipitation were recorded on the second selected day 27 July 2018. For both days the Degrees of Freedom for Signal (DFS) diagnostic was calculated. DFS diagnostic is the derivative of the analysis 
increments in the observation space with respect to the observations used in the analysis system. As proposed by Chapnik et al. (2006) DFS can be computed through the perturbations of observations:

$$
D F S=\left(\mathbf{y}^{p}-\mathbf{y}\right) \mathbf{R}^{-1}\left(\left(\Delta_{g}^{p}-\Delta_{a}^{p}\right)-\left(\Delta_{g}-\Delta_{a}\right)\right),
$$

where

$\Delta_{g}$ are the differences between perturbed and non-perturbed observations and background model state,

$\Delta_{a}$ are the differences between perturbed and non-perturbed observations and analysis model state.

The upper index $p$ denotes perturbed differences. Perturbation is done by modifying the assimilated observations by adding small value with normal distribution. The absolute DFS represent the impact of assimilating different observation types into the NWP model, in terms of amount, distribution, instrumental accuracy and observation operator definition. The results are displayed in Figs. 11 and 12. Five data types were assimilated to AROME/SHMU NWP model: observations from ground based meteorological stations (Surface Synoptic Observations (SYNOP) 5000 obs.), meteorological observations from air planes (AMDAR 2000 obs.), observations from radiosondes (TEMP $\sim 4000$ obs.), wind speed and direction estimated from geostationary meteorological satellites (Atmospheric Motion Vector (AMV) $\sim 250$ obs.) and zenith total delays estimated from hourly processing in near real-time with PNP method at SUT (ZTD 120 obs.).

The absolute impact of ZTD assimilation is low compared to other observation types. The ZTD are outnumbered by factor $\sim 42$ compared to SYNOP observations and by factor $\sim 33$ to TEMP observations. The relative DFS illustrates the impact of one assimilated observation compared to other observation types. The impact of one assimilated ZTD is dominant compared to other observation types. The decrease of relative impact of the SYNOP and TEMP observation could be related to space overlapping increments from different observations of the same type (two different observations have impact in the same spatial location). Based on these results the network densification of assimilated GNSS stations is proposed, as there are still uncovered areas in AROME/SHMU model domain (Fig. 1). The overlapping of increments shall be avoided by model tuning. 


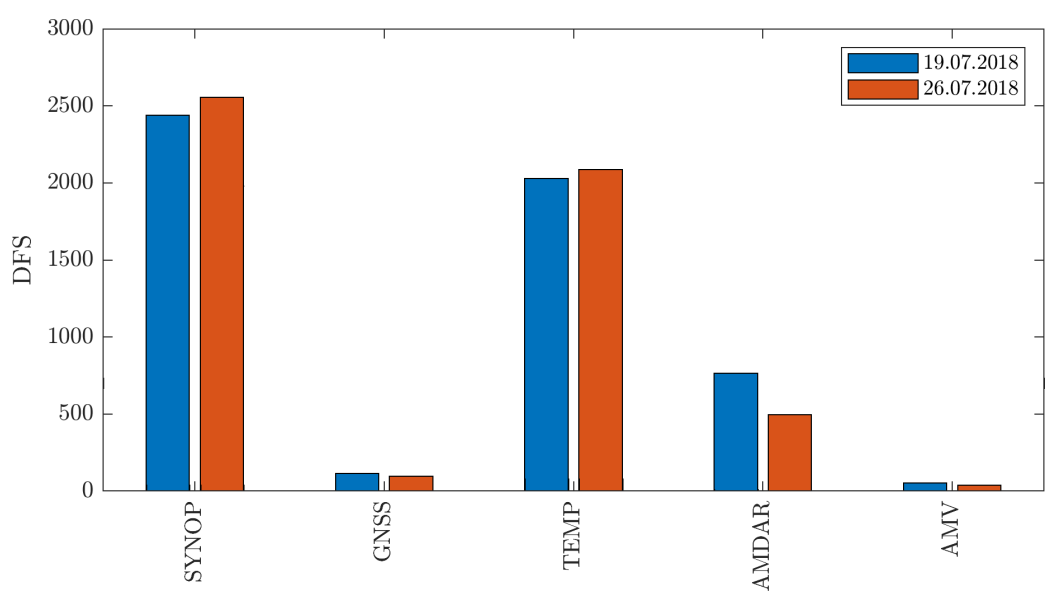

Fig. 11. Absolute DFS of observation types on 19 and 27 July 2018.

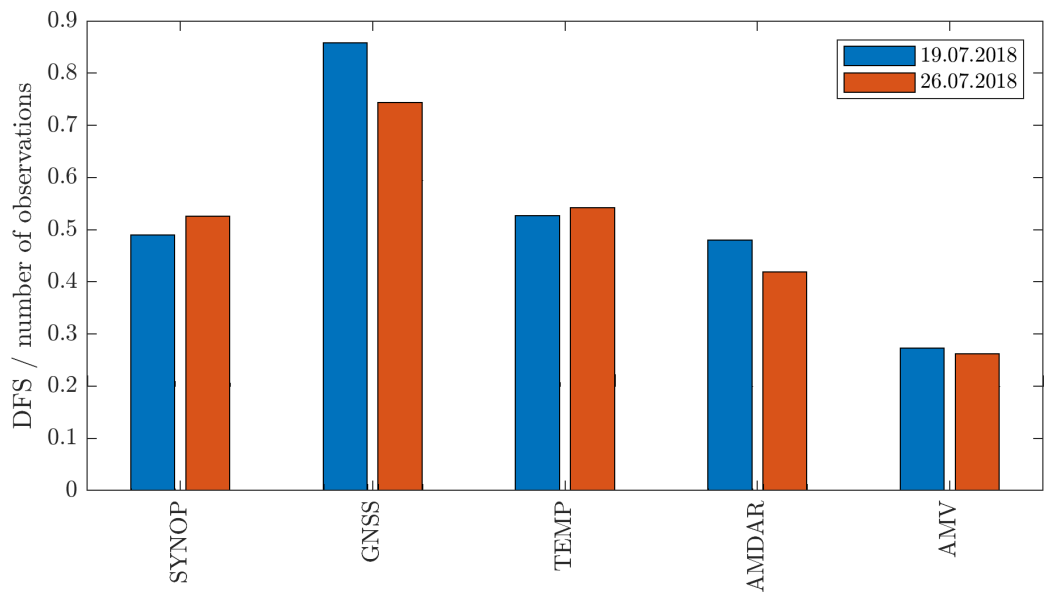

Fig. 12. Relative DFS of observation types on 19 and 27 July 2018.

\subsubsection{ZTD assimilation impact case study on precipitation fore- cast}

The impact case study of ZTD assimilation on precipitation forecast was performed on heavy rain situation on 24 and 25 August 2019. The accumulated precipitation over 24 hours were compared to INCA analysis, representing the real state. This INCA analysis is based on radar reflectivity 
measurements (which correspond to the intensity of rain) combined with automatic ground weather rain gauge measurements. Three experiments were performed. All experiments have common domain, AROME/SHMU configuration and forecasting length 24 hours. First experiment is without any data assimilation ${ }^{10}$. The second experiment is with data assimilation of SYNOP, AMDAR, TEMP and AMV observations. The zenith total delays were assimilated on top of other observations in the third experiment. The results of 24 hour precipitation forecasts are displayed in Fig. 13.
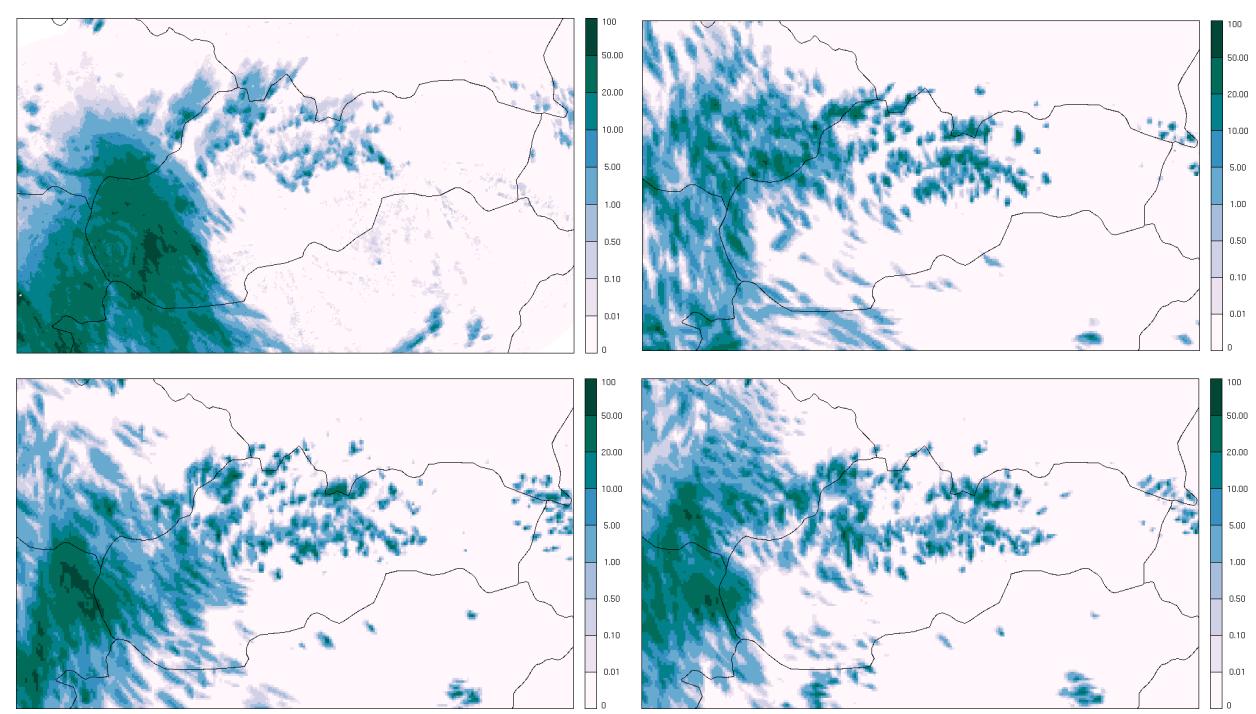

Fig. 13. Accumulated precipitation [mm] from 24 August 201912 UTC to 25 August 2019 12 UTC. Top left picture displays INCA analysis. Top right picture displays the experiment without data assimilation. Bottom left picture displays the experiment with ZTD assimilation. Bottom right picture displays the experiment without ZTD assimilation.

The INCA analysis is regarded as a representation of the true state of accumulated precipitation (top left). The AROME/SHMU model without data assimilation (top right) has in this case the most unrealistic 24 hour precipitation forecast compared to INCA analysis. The rain that has occurred in south-western Slovakia was not predicted at all and the precipitation over the mountains in northern Slovakia were overestimated. The

10 denoted as dynamic adaptation 
implementation of observation assimilation (without ZTD) with the 3D-Var method results in more realistic total amount of precipitated water (bottom right). The precipitation patterns in eastern Austria and western Slovakia are captured better, albeit still not fully correct. The best result in this case study was achieved by assimilation of all available data types (ZTD included). The ZTD have major impact on spatial location of precipitation. The extent of the territory hit by rain is more realistic with ZTD data utilization.

\section{Conclusion and perspectives}

New advanced in near-real time system for the GNSS tropospheric parameters estimation and their post processing has been developed at the Department of Theoretical Geodesy at the Slovak University of Technology in Bratislava. Its improvements with respect to the previously exploited one (Igondová and Cibulka, 2010) can be quantified as follows:

- the GNSS network is more dense in Slovakia (area per one station decreased from $8200 \mathrm{~km}^{2}$ to $2300 \mathrm{~km}^{2}$ ),

- the latency of processing is reduced four times (from 2 hours to 30 minutes),

- the frequency of processing is quadrupled (parameters are estimated every hour),

- the time span of processed datasets are two times larger (from 4 to 8 hour dataset),

- additional tropospheric parameters are estimated (north and east tropospheric horizontal gradients $G_{N}$ and $G_{E}$ ).

The most important estimated tropospheric parameter, zenith total delay, was compared to ZTD from E-GVAP and IGS solutions. These comparisons confirmed high standard of SUT solution. Furthermore, new tropospheric products were introduced on top of the standard ZTD and PWV time series and maps. The tomography of the atmosphere and the time series of tropospheric gradients are available on public web page.

We will also focus on estimation and a posteriori analysis of tropospheric horizontal gradients. These gradients are used in the estimation of STD, 
which are experimentally assimilated in AROME NWP model.

Tropospheric products derived from the GNSS network processing can provide useful complementary humidity measurements that are essential in the numerical weather prediction to forecast the high impact events associated with the moisture (Guerova et al., 2016). This was recently explored at the Slovak Hydrometeorological Institute in its experimental high resolution limited area AROME/SHMU NWP model. The potential of meteorological exploitation of ZTD data was demonstrated using Three-Dimensional variational data assimilation method. ZTD were analyzed together with other measurements to improve the NWP model initial conditions. The academic experiment assimilating only single observation showed how this measurement is horizontally and vertically propagated in the analysis. Dedicated DFS diagnostics after Chapnik et al. (2006) was applied to quantify the absolute and relative impact of various observation types within the data assimilation. Although the absolute impact of the ZTD assimilation on NWP analysis is small because the ZTD are outnumbered by other observation types, their relative impact is dominant. These results are in agreement with other studies, see Mile et al. (2019). The ZTD impact on precipitation forecast was demonstrated on the case study. The most realistic accumulated precipitation in terms of maxima as well as their spatialisation were predicted with model where all data including ZTD were used in data assimilation. This confirms the conclusions of of Mahfouf et al. (2015). Achievements described in this article suggest that a cooperation between the geodetic and meteorological communities in Slovakia shall continue. When more computer resources are acquired at SHMU, additional case studies as well as the parallel suites will be carried out to assess and quantify the impact of GNSS tropospheric products in the assimilation and forecasts of the AROME/SHMU system. Furthermore, the pilot implementation of the slant total delays data assimilation at the SHMU is planned.

Acknowledgements. The authors kindly acknowledge the support of the Jan Douša (Geodetic Observatory Pecný) for providing data from E-GVAP project for validation. The ZTD data assimilation experiments with the AROME/SHMU numerical weather prediction model were carried out within the KOSYMOKO project (OPKZPPO1-SC141-2017-25/ITMS 310011Q847). 


\section{References}

Bender M., Dick G., Ge M., Deng Z., Wickert J., Kahle H., Raabe A., Tetzlaff G., 2011: Development of a GNSS water vapour tomography system using algebraic reconstruction techniques. Adv. Space Res., 47, 10, 1704-1720, doi : 10.1016/j . asr .2010 .05 .034 .

Bevis M., Businger S., Chiswell S., Herring T. A., Anthes R. A., Rocken C., Ware R. H., 1994: GPS Meteorology: Mapping Zenith Wet Delays onto Precipitable Water. J. Appl. Meteorol. Climatol., 33, 3, 379-386, Addison Wesley, Massachusetts, doi: 10.1175/1520-0450(1994)033<0379: GMMZWD>2 . 0.CO; 2.

Böhm J., Niell A. E., Tregoning P., Schuh H., 2006a: Global Mapping Function (GMF): A new empirical mapping function based on numerical weather model data. Geophys. Res. Lett., 33, 7, L07304, doi: 10.1029/2005GL025546.

Böhm J., Werl B., Schuh H., 2006b: Troposphere mapping functions for GPS and VLBI from ECMWF operationals analysis data. J. Geophys. Res., 111, B2, B02406, doi : $10.1029 / 2005$ JB003629.

Böhm J., Heinkelmann R., Schuh H., 2007: Short Note: A global model of pressure and temperature for geodetic applications. J. Geod., 81, 10, 679-683, doi: 10.1007/s00 190-007-0135-3.

Bouttier F., Courtier P., 2002: Data assimilation concepts and methods. Meteorological Training Course Lecture Series, Education material, ECMWF, https : //www . ecmwf . int/node/16928.

Bruyninx C., Habrich H., Söhne W., Kenyeres A., Stangl G., Völksen C., 2012: Enhancement of the EUREF Permanent Network Services and Products. In: Kenyon S., Pacino M., Marti U. (Eds): Geodesy for Planet Earth. International Association of Geodesy Symposia, 136, Springer, Berlin, Heidelberg, 27-35, doi : 10.1007/978-3 -642-20338-1_4.

Chapnik B., Desroziers G., Rabier F., Talagrand O., 2006: Diagnosis and tuning of observational error in a quasi-operational data assimilation setting. Q. J. R. Meteorol. Soc., 132, 615, 543-565, doi : 10.1256/qj.04.102.

Chen G., Herring T. A., 1997: Effects of atmospheric azimuthal asymmetry on the analysis of space geodetic data. J. Geophys. Res., 102, B9, 20489- 20502, doi: 10.1029/97 JB01739.

Courtier P., Freydier C., Geleyn J.-F., Rabier F., Rochas M., 1991: The ARPEGE project at Météo-France. ECMWF, Shinfield Park, Reading, https://www .ecmwf .int/node /8798.

Dach R., Lutz S., Walser P., Fridez P., 2015: Bernese GNSS Software Version 5.2. Astronomical Institute, University of Bern. http://www. bernese.unibe.ch/docs/DOCU 52.pdf.

Dach R., Schaer S., Arnold D., Prange L., Sidorov D., Stebler P., Villiger A., Jäggi A., 2018: CODE rapid product series for the IGS. Astronomical Institute, University of Bern, http://www . aiub. unibe.ch/download/CODE.

Davis J., Herring T., Shapiro I., Rogers A., Elgered G., 1985: Geodesy by radio interferometry: Effects of atmospheric modeling errors on estimates of baseline length. 
Radio Sci., 20, 6, 1593-1607, doi: 10.1029/RS020i006p01593.

Derková M., Vivoda J., Belluš M., Španiel O., Dian M., Neštiak M., Zehnal R., 2017: Recent improvements in the ALADIN/SHMU operational system. Meteorol. J., 20, $2,45-52$.

Fischer C., Montmerle T., Berre L., Auger L., Stefanescu S. E., 2005: An overview of the variational assimilation in the ALADIN/France NWP system. Q. J. R. Meteorol. Soc., 131, 613, 3477-3492, doi: 10.1256/qj.05.115.

Guerova G., Jones J., Douša J., Dick G., de Haan S., Pottiaux E., Bock O., Pacione R., Elgered G., Vedel H., Bender M., 2016: Review of the state-of-the-art and future prospects of the ground-based GNSS meteorology in Europe. Atmos. Meas. Tech., 9, 11, 5385-5406, doi: 10.5194/amt-9-5385-2016.

Hefty J., Igondová M, Droščák B., 2009: Homogenization of long-term GPS monitoring series at permanent stations in Central Europe and Balkan Peninsula. Contrib. Geophys. Geod., 39, 1, 19-42, doi: 10.2478/v10126-009-0002-8.

Henriksen S. W., Mancini A., Chovitz B. H., 1972: The Use of Artificial Satellites for Geodesy. Geophysical Monograph No. 15, American Geophysical Union, Washington, D.C., 298 p.

Hopfield H., 1969: Two-quartic Tropospheric Refractivity Profile Correcting Satellite Data. J. Geophys. Res., 74, 18, 4487-4499, doi: 10.1029/JC074i018p04487.

Igondová M, Cibulka D., 2010: Precipitable Water Vapour and Zenith Total Delay time series and models over Slovakia and vicinity. Contrib. Geophys. Geod., 40, 4, 299312, doi : 10.2478/v10126-010-0012-6.

IGS, International GNSS Service, 2019: RINEX: The Receiver Independent Exchange Format Version 2.11. https://kb.igs.org/hc/en-us/article_attachments/115007 664947/RINEX-211.pdf.

Lafore J.-P., Stein J., Asencio N., Bougeault P., Ducrocq V., Duron J., Fischer C., Héreil P., Mascart P., Masson V., Pinty J. P., Redelsperger J. L., Richard E., VilàGuerau de Arellano J., 1998: The Meso-NH atmospheric simulation system. Part I: Adiabatic formulation and control simulations. Ann. Geophys., 16, 1, 90-109, doi : $10.1007 / \mathrm{s} 00585-997-0090-6$.

Mahfouf J-F., Ahmed F., Moll P., Teferle F., 2015: Assimilation of zenith total delays in the AROME France convective scale model: a recent assessment. Tellus A: Dynamic Meteorology and Oceanography, 67, 1, 20, doi: 10.3402/tellusa.v67.26106.

Mile M., Benáček P., Rózsa S., 2019: The use of GNSS zenith total delays in operational AROME/Hungary 3D-Var over a central European domain. Atmos. Meas. Tech., 12, 3, 1569-1579, doi: 10.5194/amt-12-1569-2019.

Mockler S. B., 1995: Water vapor in the climate system. Special Report. American Geophysical Union, 2000 Florida Ave., N.W., Washington, D.C., 20009, USA, ISBN 0-87590-865-9.

Niell A. E., 1996: Global mapping functions for the atmosphere delay at radio wavelengths. J. Geophys. Res., 101, B2, 3227-3246, doi: 10.1029/95JB03048.

Poli P., Moll P., Rabier F., Desroziers G., Chapnik B., Berre L., Healy S. B., Andersson E., El Guelai F.-Z., 2007: Forecast impact studies of zenith total delay data from 
European near real-time GPS stations in Météo France 4DVAR. J. Geophys. Res.: Atmospheres, 112, D6, D06114, doi: 10.1029/2006JD007430.

Saastamoinen J., 1972: Atmospheric Correction for the Troposphere and Stratosphere in Radio Ranging Satellites. In: Henriksen S. W., Mancini A., Chovitz B. H.: The Use of Artifical Satellites for Geodesy, 15, 247-251. Washington, D.C., doi: 10.1029/ GM015p0247.

Sehnal M., Mayer D., Mitterschiffthaler P., 2019: EUREF Analysis and Data Center at BEV Vienna. VGI - Österreichische Zeitschrift für Vermessung und Geoinformation, 2, 116-118. ISSN 1605-1653.

Seity Y., Brousseau P., Malardel S., Hello G., Bénard P., Bouttier F., Lac C., Masson V., 2011: The AROME-France convective-scale operational model. Mon. Weather Rev., 139, 3, 976-991, doi: 10.1175/2010MWR3425.1.

Storto A., Randriamampianina R., 2010: A new bias correction scheme for assimilating GPS zenith tropospheric delay estimates. Idojárás ? Quarterly Journal of the Hungarian Meteorological Service, 114, 4, 237-250.

Termonia P., Fischer C., Bazile E., Bouyssel F., Brožková R., Bénard P., Bochenek B., Degrauwe D., Derková M., El Khatib R., Hamdi R., Mašek J., Pottier P., Pristov N., Seity Y., Smolíková P., Španiel O., Tudor M., Wang Y., Wittmann C., Joly A., 2018: The ALADIN System and its canonical model configurations AROME CY41T1 and ALARO CY40T1. Geosci. Model Dev., 11, 1, 257-281, doi : $10.5194 /$ gmd-11-257-2018. 